\title{
IMPACT OF NONLINEARITY OF THE CONTACT LAYER BETWEEN ELEMENTS JOINED IN A MULTI-BOLTED SYSTEM ON ITS PRELOAD
}

\author{
R. GRZEJDA \\ Faculty of Mechanical Engineering and Mechatronics \\ West Pomeranian University of Technology, Szczecin \\ 19 Piastów Ave., 70-310 Szczecin, POLAND \\ E-mail: rafal.grzejda@zut.edu.pl
}

\begin{abstract}
The paper deals with modelling and calculations of asymmetrical multi-bolted joints at the assembly stage. The physical model of the joint is based on a system composed of four subsystems, which are: a couple of joined elements, a contact layer between the elements, and a set of bolts. The contact layer is assumed as the Winkler model, which can be treated as a nonlinear or linear model. In contrast, the set of bolts are modelled using simplified beam models, known as spider bolt models. The theorem according to which nonlinearity of the contact layer has a negligible impact on the final preload of the joint in the case of its sequential tightening has been verified. Results of sample calculations for the selected multi-bolted system, in the form of diagrams of preloads in the bolts as well as normal contact pressure between the joined elements during the assembly process and at its end, are presented.
\end{abstract}

Key words: multi-bolted joint, systemic approach, assembly state, preload.

\section{Introduction}

In general, it can be assumed that a multi-bolted joint in the assembly state is loaded only with normal forces (Grzejda [1]). Considering contact phenomena between the joined elements in this case, it is sufficient to take into account normal characteristics of the contact joint (for a review, see Abdo [2]). Such characteristics can be represented with a good approximation by an exponential function (Grudziński and Kostek [3], Kostek [4], Misra and Huang [5]). However, the extent of this function depends on values of loads acting on the contact joint. In the case of a contact joint between the elements joined in preloaded multi-bolted joints, it can be adopted that the contact characteristics are already close to linear. This follows directly from the progressive preloading of the bolts in the assembly process (Abid and Nash [6], Kumakura and Saito [7]), which in turn is synonymous with the increasingly complete clamping of the contact layer between the joined elements. Then, usually nonlinear characteristics of the normal deformation may be replaced by their linear counterparts. The aim of this study is to show such a phenomenon based on the multi-bolted joint model presented in Grzejda [8].

The most popular method dedicated to modelling of multi-bolted joints is the finite element method (FEM). It is used, taking into consideration the following kinds of contact elements:

- linear contact elements with constant values of the contact stiffness coefficients, available in commercial finite element analysis systems (Gerami et al. [9], Maggi et al. [10], Pirmoz [11], Pirmoz et al. [12], Saedi Daryan et al. [13], Shi et al. [14], Wang et al. [15]),

- nonlinear contact elements (Bucher and Ebert [16], Girão Coelho [17]).

These works are focused on conventional types of symmetrical joints:

- bolted angle connections (Pirmoz [11], Pirmoz et al. [12], Saedi Daryan et al. [13]),

- bolted end-plate connections (Gerami et al. [9], Maggi et al. [10], Shi et al. [14], Girão Coelho [17]),

- bolted flange connections (Wang et al. [15], Bucher and Ebert [16]).

In all the above mentioned papers, a systemic approach to modelling, calculations and analysing multi-bolted joints is not taken into account. 
The joined elements in FE-models of multi-bolted joints are generally created as a spatial body, but the bolts are modelled in different ways. Aside from spatial models of the bolts (Gerami et al. [9], Maggi et al. [10], Pirmoz [11], Shi et al. [14], Wang et al. [15], Girão Coelho [17]), the following substitute bolt FEmodels are applied:

- spring models (Li et al. [18], Luan et al. [19]),

- beam models (Karagiannis et al. [20]),

- rigid body bolt models with a flexible plain part of the bolt and a rigid bolt head (Aguirrebeitia et al. [21], Grzejda [22], Hammami et al. [23]),

- spider bolt models (Grzejda [24], Kim et al. [25]).

Taking into consideration the above fact, the FEM is also used in this paper for modelling and calculations of the multi-bolted system at the assembly state. At the same time the spider bolt model as a bolt model has been selected.

\section{Physical model of the multi-bolted system}

A general structure of the multi-bolted system model results from an idea presented in Grzejda [24]. The model of the system is based on a flexible flange element that is fastened to a flexible support by means of $k$ bolt elements, modelled using the spider bolt model (Kim et al. [25]), preloaded by forces $F_{m i}$ (Fig.1.).

b)
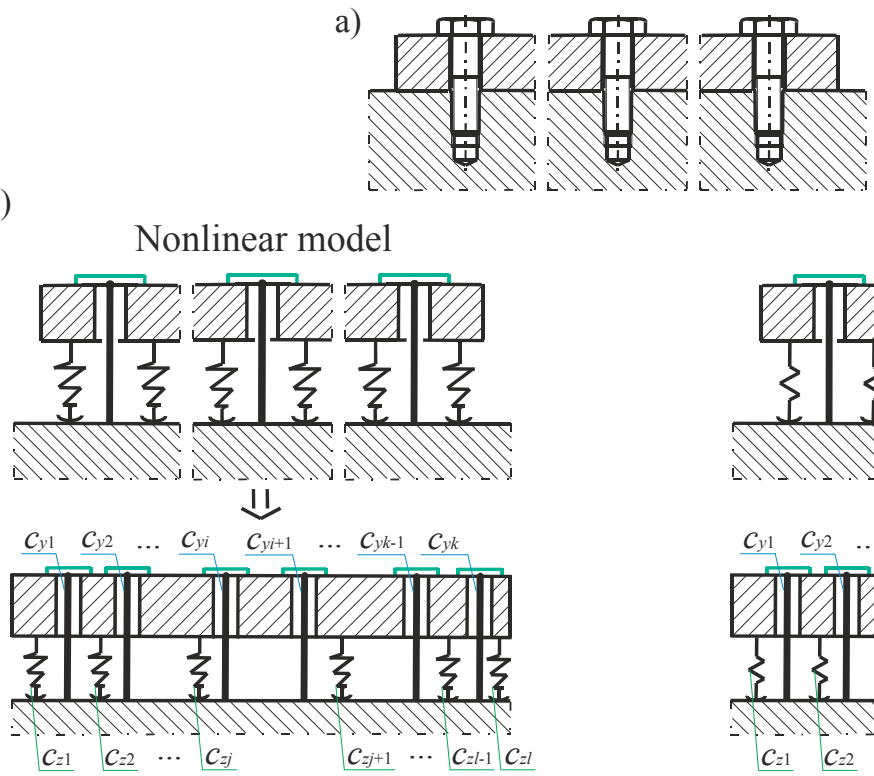

Linear model
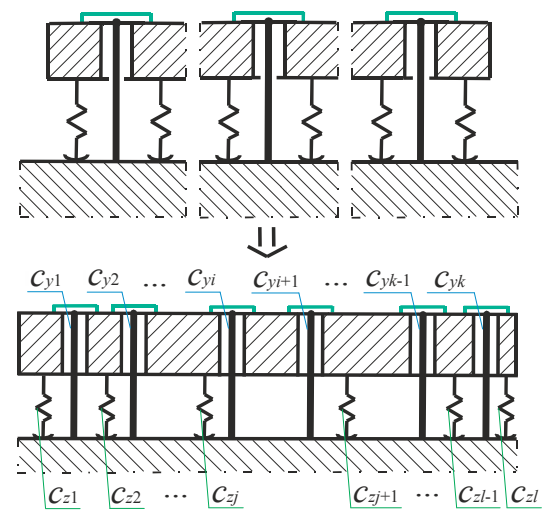

c)

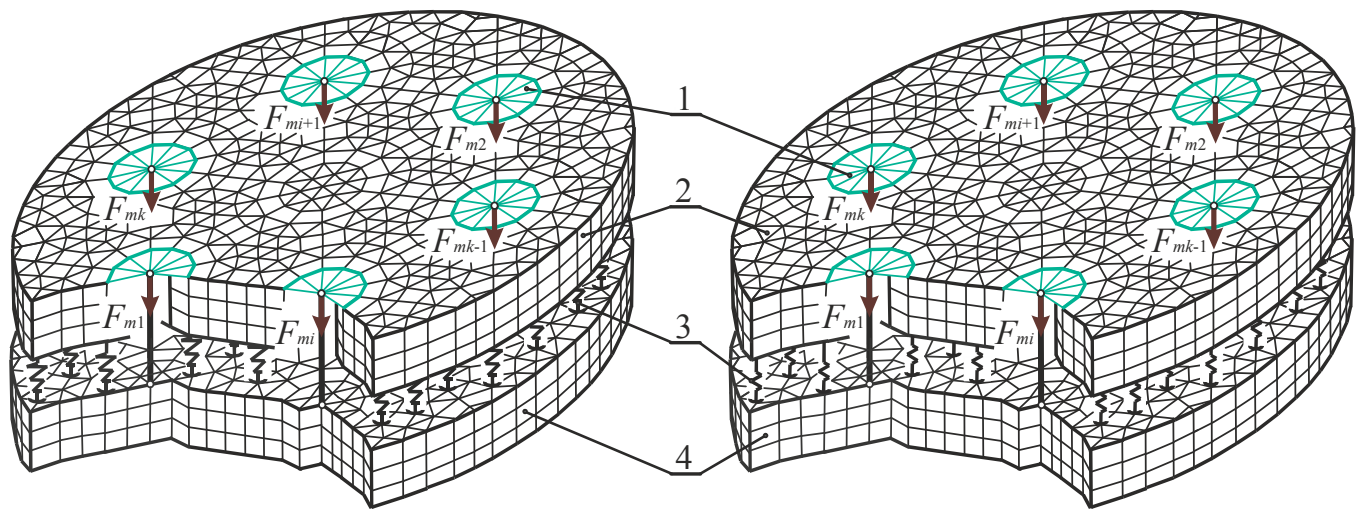

Fig.1. Multi-bolted system: a) diagram, b) description of system spring properties, c) FEM-models. 
Between the flange element and the support, a contact layer of the Winkler model type is introduced. The contact layer can be treated as a nonlinear or linear model and is described by means of $l$ one-sided spring elements, characterized by the following relationship

$$
R_{j}=A_{j} \cdot f\left(u_{j}\right)
$$

where: $R_{j}$ is the force in the centre of the $j$-th elementary contact area, $A_{j}$ is the $j$-th elementary contact area, and $u_{j}$ is the deformation of the $j$-th nonlinear or linear spring element of the contact layer (for $j=1,2, \ldots, l$ ). order:

The above-mentioned parts of the multi-bolted joint constitute a system according to the following

- $\boldsymbol{B}$ - set of bolts,

- $\boldsymbol{F}$ - flexible flange element,

- $\boldsymbol{C}$ - Winkler type contact layer,

- $\boldsymbol{S}$ - flexible support.

The equation of system equilibrium (Fig.1c) can be represented as

$$
\boldsymbol{K} \cdot \boldsymbol{q}=\boldsymbol{p}
$$

where: $\boldsymbol{K}$ is the stiffness matrix, $\boldsymbol{q}$ is the displacements vector, and $\boldsymbol{p}$ is the loads vector.

Adopting the division of the system into four subsystems, Eq.(2.2) can be transformed into a form

$$
\left[\begin{array}{cccc}
\boldsymbol{K}_{B B} & \boldsymbol{K}_{B F} & \mathbf{0} & \boldsymbol{K}_{B S} \\
\boldsymbol{K}_{F B} & \boldsymbol{K}_{F F} & \boldsymbol{K}_{F C} & \mathbf{0} \\
\mathbf{0} & \boldsymbol{K}_{C F} & \boldsymbol{K}_{C C} & \boldsymbol{K}_{C S} \\
\boldsymbol{K}_{S B} & \mathbf{0} & \boldsymbol{K}_{S C} & \boldsymbol{K}_{S S}
\end{array}\right] \cdot\left[\begin{array}{c}
\boldsymbol{q}_{B} \\
\boldsymbol{q}_{F} \\
\boldsymbol{q}_{C} \\
\boldsymbol{q}_{S}
\end{array}\right]=\left[\begin{array}{c}
\boldsymbol{p}_{B} \\
\boldsymbol{p}_{F} \\
\boldsymbol{p}_{C} \\
\boldsymbol{p}_{S}
\end{array}\right]
$$

where: $\boldsymbol{K}_{a a}$ is the stiffness matrix of the $a$-th subsystem, $\boldsymbol{K}_{a b}$ is the matrix of elastic couplings between the $a$-th and $b$-th subsystems, $\boldsymbol{q}_{a}$ is the displacements vector of the $a$-th subsystem, and $\boldsymbol{p}_{a}$ is the loads vector of the $a$ th subsystem ( $a, b$ - symbols of the subsystems, $a \in\{B, F, C, S\}, b \in\{B, F, C, S\})$.
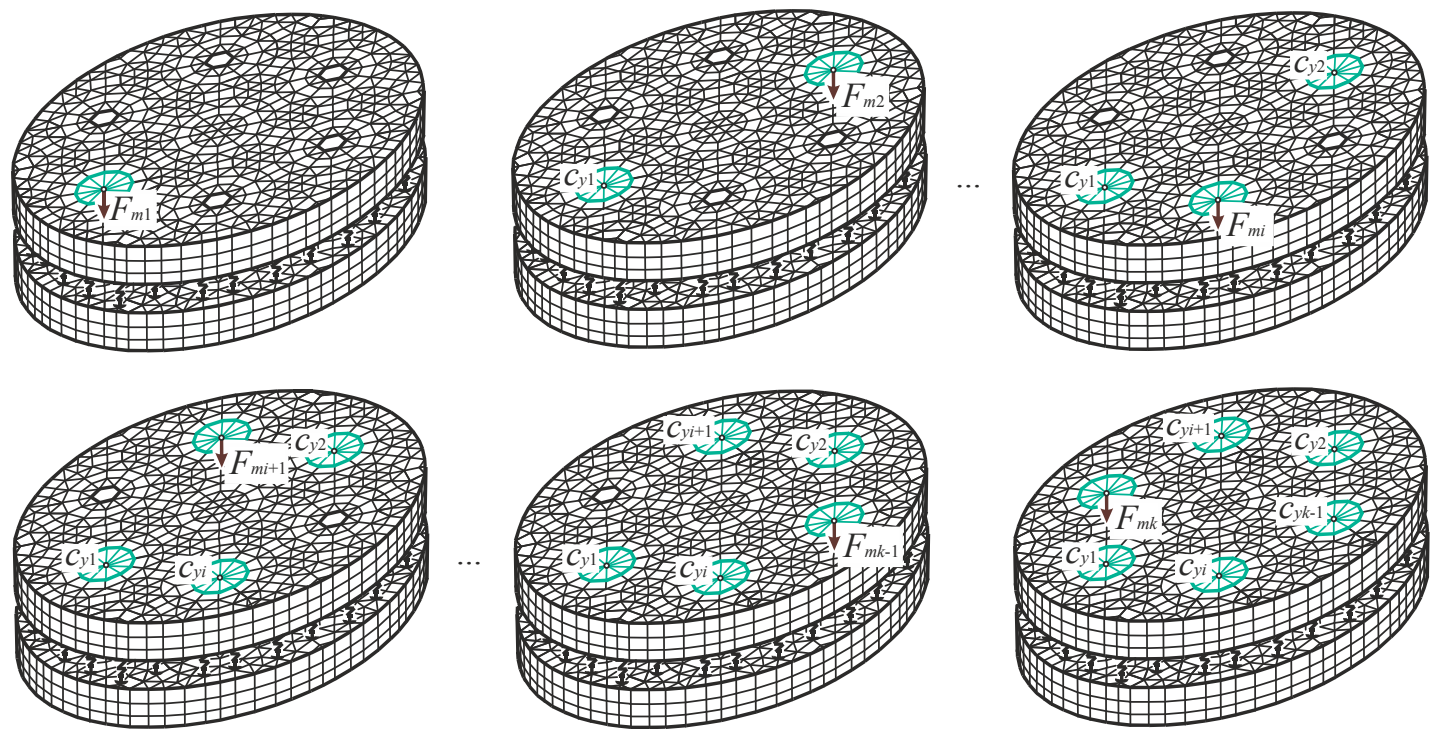

Fig.2. Sequential preloading of bolts in the system. 
On the grounds of the so defined model of the multi-bolted system, diagrams of preloads in the bolts as well as normal contact pressure between the joined elements during the assembly process and at its end can be evaluated.

The assembly process of the system consists of $k$ steps, in pursuance of the number of bolts in the system. During the first bolt preloading, the system is composed of joined element, and the nonlinear contact layer between them. In this first step, the system is assembled with only one bolt and loaded by the force $F_{m l}$ which means the preload of the bolt No.1 (Fig.2).

In the next steps of the system preloading (for $i=2, \ldots, k$ ), the next spider bolt model is taken into account. Therefore, in Eq.(2.3) the stiffness matrix of the bolts subsystem $\boldsymbol{K}_{B B}$ has been complemented with the elements, which are preloaded in the current step of the assembly process. However, in the current step of the system preloading, the stiffness matrix $\boldsymbol{K}_{B B}$ is a constant part of the system stiffness matrix $\boldsymbol{K}$, and the stiffness matrices $\boldsymbol{K}_{C C}, \boldsymbol{K}_{C F}$ and $\boldsymbol{K}_{C S}$ are a variable part of the system stiffness matrix $\boldsymbol{K}$.

In each calculation step, search for a solution to Eq.(2.3) is conducted in an iterative process. For the nonlinear model of the multi-bolted system the secant method is used, while for its linear model the linearized normal characteristics are used directly. In the case of the first bolt preloading, the linearization runs according to the way shown in Fig.3a, starting from the origin of the coordinate system. In contrast, in the case of the next bolt preloading, it starts with the working points $L_{j}$ corresponding to the preload of the $j$-th nonlinear spring in the previous step of the calculation (Fig.3b).
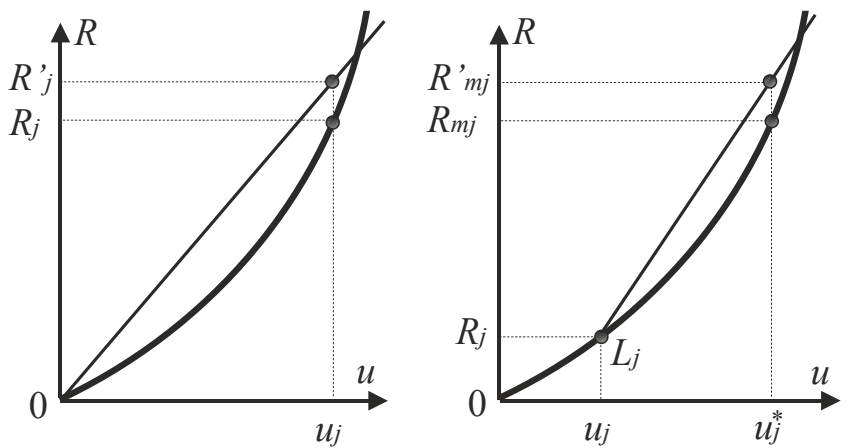

Fig.3. Linearization of a curve by the secant method: a) for the first bolt preloading, b) for the next bolt preloading.

In every step of multi-bolted system preloading the linearization process is kept running until the following condition has been met

$$
\left|\frac{R_{c}^{\prime}-R_{c}}{R_{c}}\right| \leq \alpha
$$

where: $R_{c}^{\prime}$ is the reaction in the $j$-th nonlinear spring obtained from the linearization, $c$ is the index indicating the case of the calculation process $(c \in\{j, m j\})$, and $\alpha$ is the admissible error of the linearization.

Based on the received values of normal deformation of the $j$-th nonlinear/linear spring $u_{j}$, normal contact pressure $p_{j}$ on the $j$-th elementary contact surface can be determined according to the relationship

$$
p_{j}=\frac{c_{z j} \cdot u_{j}}{A_{j}}
$$

where: $c_{z j}$ is the stiffness coefficient of the $j$-th nonlinear/linear spring model (Fig.1b). 
The bolt lying in the region of the smallest average value of normal pressure on the contact surface of joined elements is selected as the next bolt for preloading.

\section{Calculations of the exemplary multi-bolted system}

According to the proposed method, computations of an asymmetrical multi-bolted system were carried out. A simplified FEM-based model of the system is shown in Fig.4a. The model was built and all analyses were performed using the Midas NFX 2017 program. The joint is fastened using seven M10 bolts. The optimum bolt preloading sequence designated for the adopted multi-bolted system is parenthesized in Fig.4a.

a)

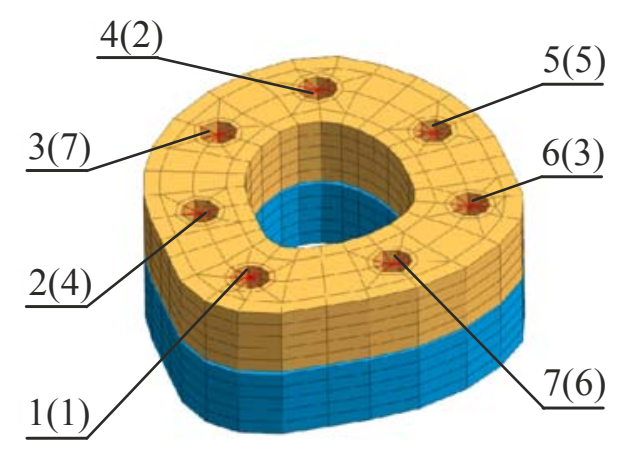

b)

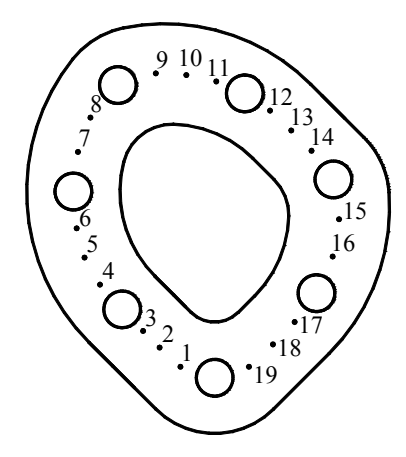

Fig.4. Assumed multi-bolted system: a) FEM-based model of the multi-bolted system with the adopted numbering of the bolts and the tightening sequence given in parentheses, b) nodes adopted to describe normal contact pressure distribution.

The calculations were carried out for the joined elements thickness $h$ equal to $20 \mathrm{~mm}$ and the initial preload of the bolts $F_{m i}$ equal to $20 \mathrm{kN}$. The stiffness characteristics of springs in the contact layer are described by the following functions:

- for the nonlinear model (Grzejda [26])

$$
R_{j}=A_{j} \cdot\left(3.428 \cdot u_{j}^{1.657}\right)
$$

- for the linear model (Grzejda [27])

$$
R_{j}=A_{j} \cdot\left(26.873 \cdot u_{j}\right)=
$$

Results of calculations were put together in graphs shown in Figs 5 to 7. In Fig.5 variations of the preload in individual bolts during the assembly process are shown as follows:

- in the first line - preload changes in the bolt No.1 (preloaded as the first bolt),

- in the second line - preload changes in bolts No. 4 and 3 (preloaded as the second and the seventh bolt, respectively),

- in the third line - preload changes in bolts No. 6 and 7 (preloaded as the third and the sixth bolt, respectively),

- in the fourth line - preload changes in bolts No. 2 and 5 (preloaded as the fourth and the fifth bolt, respectively).

In Fig.6 the scatter of final preload values in the bolts at the end of the assembly process is presented. 

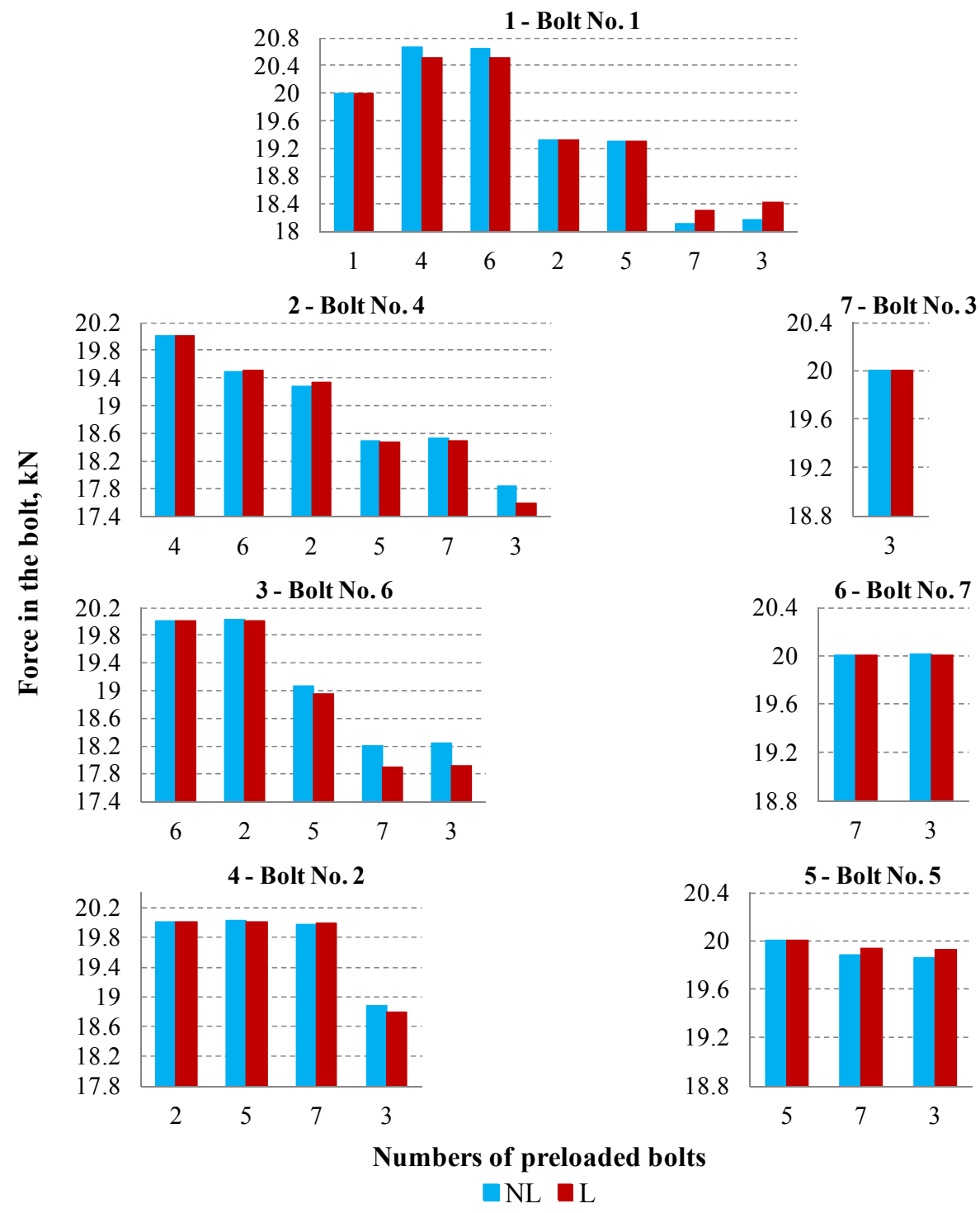

Fig.5. Preload values during the assembly process.

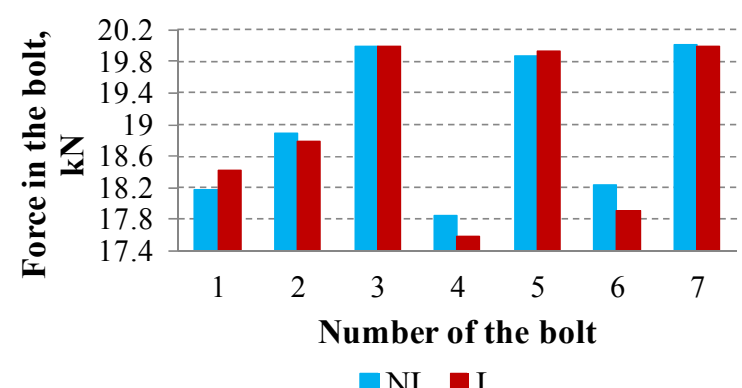

Fig.6. Preload values at the end of the assembly process. 
The relative difference between the obtained final preloads can be presented on by the formula

$$
Z_{1}=\frac{F_{m i}^{L}-F_{m i}^{N L}}{F_{m i}^{N L}} \cdot 100 \%
$$

where: $F_{m i}^{L}$ is the preload of the $i$-th bolt according to the linear model of the multi-bolted system, and $F_{m i}^{N L}$ is the preload of the $i$-th bolt in accordance with the nonlinear model of the multi-bolted system.

$Z_{l}$ index values are set up in Tab.1.

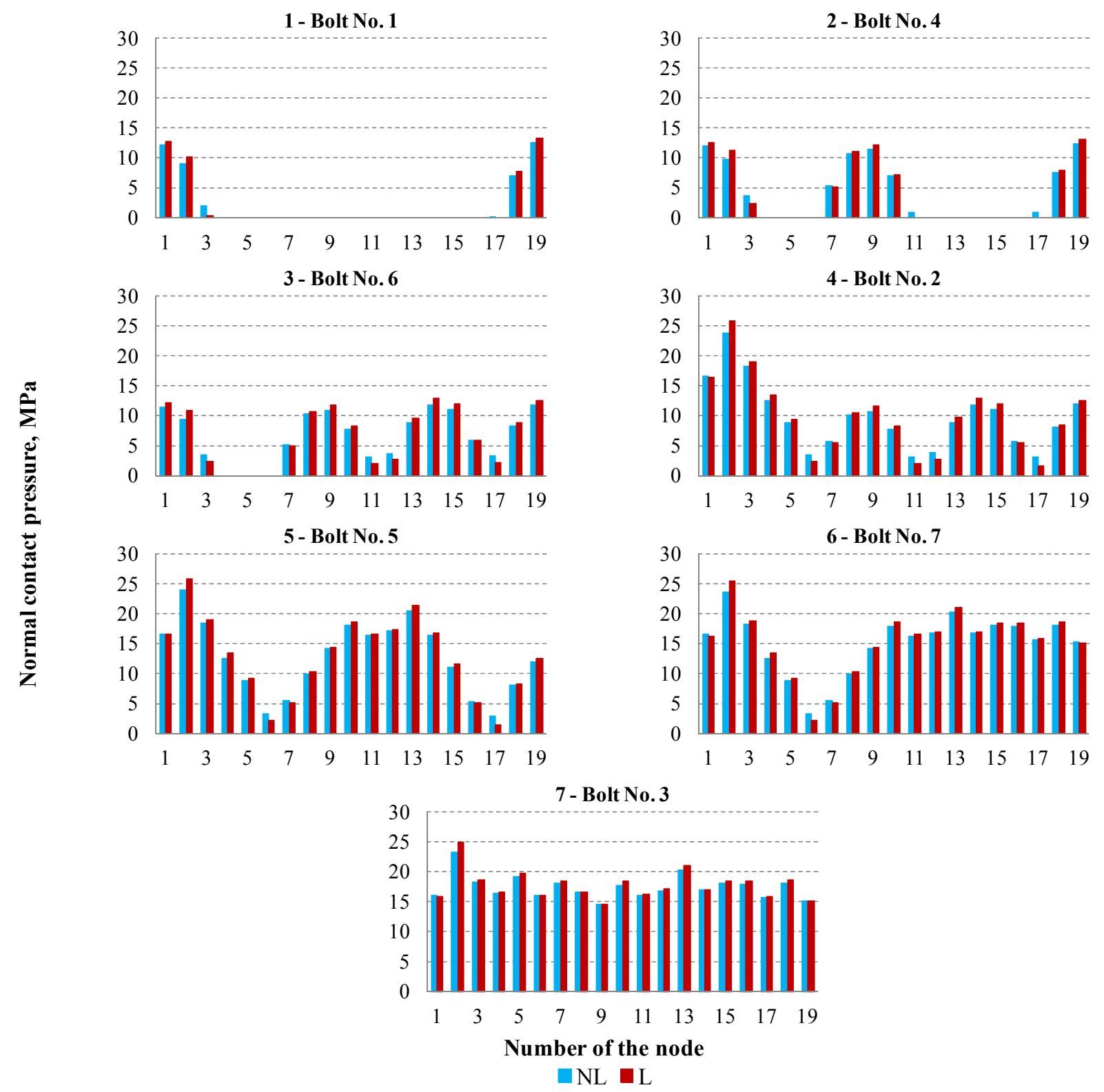

Fig.7. Diagrams of normal contact pressure during the assembly process. 
Table $1 . Z_{l}$ index values.

\begin{tabular}{|c|c|c|c|c|c|c|c|}
\hline$i$ & 1 & 2 & 3 & 4 & 5 & 6 & 7 \\
\hline$Z_{1}, \%$ & 1.31 & -0.52 & 0 & -1.46 & 0.35 & -1.85 & -0.09 \\
\hline
\end{tabular}

The adoption of the linear contact layer between the joined elements in the proposed multi-bolted system model may lead to an underestimation of preloads of the bolts by less than $2 \%$.

The distribution of normal contact pressure on elementary surfaces on the line joining the nodes defined in Fig. $4 \mathrm{~b}$ during the assembly process of the multi-bolted system is shown in Fig.7.

The assessment of final values of normal contact pressure can be made on the basis of the $Z_{2}$ index

$$
Z_{2}=\frac{p_{n}^{L}-p_{n}^{N L}}{p_{n}^{N L}} \cdot 100 \%
$$

where: $p_{n}^{L}$ is the value of normal contact pressure on the $n$-th contact surface, linked to the $n$-th node (Fig.4b, $n=1,2, \ldots, 19$ ), according to the linear model of the multi-bolted system, and $p_{n}^{N L}$ is the value of normal contact pressure on the line joining the nodes shown in Fig.4b, in accordance with the nonlinear model of the multi-bolted system.

The $Z_{2}$ index values are specified in Tab.2.

Table 2. $Z_{2}$ index values.

\begin{tabular}{|c|c|c|c|c|c|c|c|c|c|c|}
\hline Node's number & 1 & 2 & 3 & 4 & 5 & 6 & 7 & 8 & 9 & 10 \\
\hline$Z_{2}, \%$ & -1.17 & 7.30 & 2.16 & 1.00 & 3.04 & 0.73 & 2.17 & 0.56 & 0.02 & 3.47 \\
\hline Node's number & 11 & 12 & 13 & 14 & 15 & 16 & 17 & 18 & 19 & \\
\hline$Z_{2}, \%$ & 2.01 & 1.59 & 4.32 & 0,69 & 2.50 & 3.29 & 1.59 & 2.96 & -0.25 & \\
\hline
\end{tabular}

The adoption of the linear contact layer between the joined elements in the proposed multi-bolted system model may lead to an overestimation of normal contact pressure between the elements by less than $7.3 \%$.

\section{Conclusions}

In the case of preloaded multi-bolted systems, nonlinearity of the contact layer between the joined elements may have a marginal impact on the final preload values in the bolts as well as on the final normal contact pressure between the joined elements. Hence, for modelling, calculations and analysis of such joints, linear models of the contact layer between the joined elements can be successfully applied. At the same time, due to this fact one obtains a relevantly higher efficiency of modelling, which is caused by both a smaller complexity of the problem and an appreciably shorter process time.

\section{Nomenclature}

$$
\begin{aligned}
A_{j} & -j \text {-th elementary contact area, }\left[\mathrm{mm}^{2}\right], \text { Eq. }(2.1) \\
\alpha & - \text { admissible error of linearization, Eq. }(2.4) \\
c_{y i} & - \text { stiffness coefficient of the } i \text {-th bolt's model, }[\mathrm{kN} / \mathrm{mm}]
\end{aligned}
$$


$c_{z j}-$ stiffness coefficient of the $j$-th nonlinear/linear spring element of the contact layer, $[\mathrm{kN} / \mathrm{mm}]$, Eq. (2.5)

$F_{m i}$ - preload of the $i$-th bolt, $[k N]$

$h$ - thickness of the joined elements, $[\mathrm{mm}]$

$\boldsymbol{K}$ - stiffness matrix, Eq.(2.2)

$\boldsymbol{p}$ - loads vector, Eq.(2.2)

$p_{j}-$ normal contact pressure on the $j$-th elementary contact surface, $[M P a]$, Eq.(2.5)

$\boldsymbol{q}$ - displacements vector, Eq.(2.2)

$R_{j} \quad$ - force in the centre of the $j$-th elementary contact area, $[k N]$, Eq.(2.1)

$u_{j}$ - deformation of the $j$-th nonlinear/linear spring element of the contact layer, $[\mathrm{mm}]$, Eq.(2.1)

$Z_{1}-$ accuracy index, [\%], Eq.(3.3)

$Z_{2}-$ accuracy index, [\%], Eq.(3.4)

\section{Superscripts}

$L$ - linear model of the contact layer between elements joined in a multi-bolted system

$N L$ - nonlinear model of the contact layer between elements joined in a multi-bolted system

\section{Subscripts}

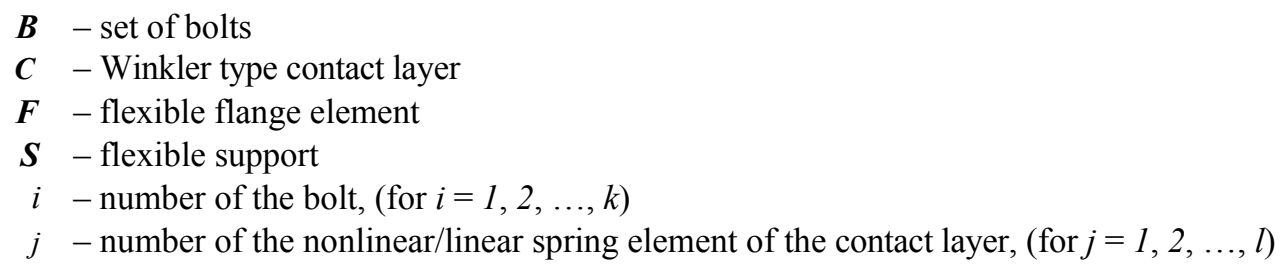

\section{References}

[1] Grzejda R. (2016): Modelling nonlinear multi-bolted connections: A case of the assembly condition. - Proc. of the 15th International Scientific Conference "Engineering for Rural Development 2016“, Jelgava: Latvia University of Agriculture, pp.329-335.

[2] Abdo J. (2006): Modeling of frictional contact parameters of mechanical systems. - International Journal of Applied Mechanics and Engineering, vol.11, No.3, pp.449-465.

[3] Grudziński K. and Kostek R. (2007): An analysis of nonlinear normal contact microvibrations excited by a harmonic force. - Nonlinear Dynamics, vol.50, No.4, pp.809-815.

[4] Kostek R. (2013): An analysis of the primary and superharmonic contact resonances - Part 2. - Journal of Theoretical and Applied Mechanics, vol.51, No.3, pp.687-696.

[5] Misra A. and Huang S. (2011): Effect of loading induced anisotropy on the shear behavior of rough interfaces. Tribology International, vol.44, No.5, pp.627-634.

[6] Abid M. and Nash D.H. (2006): Structural strength: Gasketed vs non-gasketed flange joint under bolt up and operating condition. - International Journal of Solids and Structures, vol.43, No.14-15, pp.4616-4629.

[7] Kumakura S. and Saito K. (2003): Tightening sequence for bolted flange joint assembly. - Proc. of the 2003 ASME Pressure Vessels and Piping Conference, Analysis of Bolted Joints, Cleveland: ASME, pp.9-16.

[8] Grzejda R. (2016): Modelling nonlinear preloaded multi-bolted systems on the operational state. - Engineering Transactions, vol.64, No.4, pp.525-531.

[9] Gerami M., Saberi H., Saberi V. and Saedi Daryan A. (2011): Cyclic behavior of bolted connections with different arrangement of bolts. - Journal of Constructional Steel Research, vol.67, No.4, pp.690-705. 
[10] Maggi Y.I., Gonçalves R.M., Leon R.T. and Ribeiro L.F.L. (2005): Parametric analysis of steel bolted end plate connections using finite element modeling. - Journal of Constructional Steel Research, vol.61, No.5, pp.689-708.

[11] Pirmoz A. (2011): Performance of bolted angle connections in progressive collapse of steel frames. - The Structural Design of Tall and Special Buildings, vol.20, No.3, pp.349-370.

[12] Pirmoz A., Seyed Khoei A., Mohammadrezapour E. and Saedi Daryan A. (2009): Moment-rotation behavior of bolted top-seat angle connections. - Journal of Constructional Steel Research, vol.65, No.4, pp.973-984.

[13] Saedi Daryan A., Ziaei M. and Amirodin Sadrnejad S. (2011): The behavior of top and seat bolted angle connections under blast loading. - Journal of Constructional Steel Research, vol.67, No.10, pp.1463-1474.

[14] Shi G., Shi Y., Wang Y. and Bradford M.A. (2008): Numerical simulation of steel pretensioned bolted end-plate connections of different types and details. - Engineering Structures, vol.30, No.10, pp.2677-2686.

[15] Wang Y.Q., Zong L. and Shi Y.J. (2013): Bending behavior and design model of bolted flange-plate connection.Journal of Constructional Steel Research, vol.84, pp.1-16.

[16] Bucher Ch. and Ebert M. (2002): Nonlinear calculation of steel flange connections with measured imperfections (in German). - Stahlbau, vol.71, No.7, pp.516-522.

[17] Girão Coelho A.M. (2013): Rotation capacity of partial strength steel joints with three-dimensional finite element approach. - Computers and Structures, vol.116, pp.88-97.

[18] Li Z., Soga K., Wang F., Wright P. and Tsuno K. (2014): Behaviour of cast-iron tunnel segmental joint from the $3 D$ FE analyses and development of a new bolt-spring model. - Tunnelling and Underground Space Technology, vol.41, pp.176-192.

[19] Luan Y., Guan Z.-Q., Cheng G.-D. and Liu S. (2012): A simplified nonlinear dynamic model for the analysis of pipe structures with bolted flange joints. - Journal of Sound and Vibration, vol.331, No.2, pp.325-344.

[20] Karagiannis V., Málaga-Chuquitaype C. and Elghazouli A.Y. (2017): Behaviour of hybrid timber beam-to-tubular steel column moment connections. - Engineering Structures, vol.131, pp.243-263.

[21] Aguirrebeitia J., Abasolo M., Avilés R. and de Bustos I.F. (2012): General static load-carrying capacity for the design and selection of four contact point slewing bearings: Finite element calculations and theoretical model validation. - Finite Elements in Analysis and Design, vol.55, pp.23-30.

[22] Grzejda R. (2017): Modelling nonlinear multi-bolted systems on the assembly state. - Procedia Engineering, vol.206, pp.1808-1812.

[23] Hammami C., Balmes E. and Guskov M. (2016): Numerical design and test on an assembled structure of a bolted joint with viscoelastic damping. - Mechanical Systems and Signal Processing, vol.70-71, pp.714-724.

[24] Grzejda R. (2016): New method of modelling nonlinear multi-bolted systems, In: Advances in Mechanics: Theoretical, Computational and Interdisciplinary Issues (M. Kleiber, T. Burczyński, K. Wilde, J. Górski, K. Winkelmann, Ł. Smakosz, Ed.). - Leiden: CRC Press.

[25] Kim J., Yoon J.-C. and Kang B.-S. (2007): Finite element analysis and modeling of structure with bolted joints. Applied Mathematical Modelling, vol.31, No.5, pp.895-911.

[26] Grzejda R. (2014): Designation of a normal stiffness characteristic for a contact joint between elements fastened in a multi-bolted connection. - Diagnostyka, vol.15, No.2, pp.61-64.

[27] Grzejda R. (2016): Non-linearity of the contact layer between elements joined in a multi-bolted connection and the preload of the bolts. - Combustion Engines, vol.55, No.2, pp.3-8.

Received: May 24, 2017

Revised: May 31, 2017 